\title{
FOREWORD TO THE TENTH VOLUME
}

IN my foreword to the first volume of Paraplegia, I defined the purpose of our journal firstly to serve as a structure for uniting the Society's widely scattered members but, above all, to form a central international source of information for all groups of physicians and surgeons and other scientific workers actively engaged or interested in the manifold aspects of paraplegia and tetraplegia.

Looking back, I am happy to say that our journal has fulfilled this purpose. Colleagues attending the annual scientific meetings held in conjunction with the International Stoke Mandeville Games for the Paralysed, either at Stoke Mandeville in Aylesbury or at Rome, Tokyo and Israel, have increased in numbers year after year. Over the years, our Society has been moulded into a large family bound together by common interests and friendship. Many excellent clinical as well as experimental papers have been presented at these meetings, and most important of all these have been followed by a frank exchange of discussion and experience, which no doubt has helped to widen our concept and understanding of the complex problems associated with spinal paraplegia and tetraplegia. Thus, the high scientific standard of the journal has been maintained.

One of the most important developments during the last ten years has been the increase of spinal injuries centres set up in various countries, which have themselves become sources of experience and knowledge.

However, throughout the many journeys undertaken, at the invitation of governments and organisations throughout the world, I have been aware that there is still an astonishing lack of progress in this complex subject of medicine. This applies by no means just to the so-called developing countries but to countries whose standard of medicine in other spheres is of the highest order. I hope that my visits have been of help to members of our Society in their struggle to improve conditions in their countries, and in this respect New Zealand may be quoted as an example, where the government has now allocated money to set up two spinal injuries centres.

It has become apparent to us all that one of the outstanding problems of today is the management of the tetraplegic patient, not only from the medical point of view but even more from the aspect of domestic and social resettlement. In all countries, this is now an ever-increasing problem, and the active co-operation on the part of the authorities concerned in every country to deal with this social problem still leaves much to be desired. Members of our Society must not cease in their efforts to stimulate the authorities and the public as a whole to work out satisfactory solutions to enable these severely disabled people, who can now survive for many years, to live a purposeful life.

There is now an increased awareness on the part of the medical profession that the subject of spinal paraplegia and tetraplegia is a multi-disciplinary specialty in its own right, deserving an equal status to other specialties in medicine and surgery. There is still, however, a great lack of understanding amongst Universities to give our speciality its rightful place within the medical faculty and in their undergraduate and postgraduate teaching programmes, with some notable exceptions, such as Toronto, Geneva, Heidelberg, Melbourne, and Perth (Western 
Australia). One can only hope that the example of these enlightened Universities will spread to other parts of the world.

In conclusion, I feel that our Society and its journal in this short space of time have made good progress in fulfilling the philosophy with which Paraplegia was started.

However, it is still 'a long way to Tipperary!'

Sir Ludwig GuttmanN 